\title{
Monoclonal antibody preparation of Golgi phosphoprotein 2 and preliminary application in the early diagnosis of hepatocellular carcinoma
}

\author{
QIANG JU*, YANJIE ZHAO*, YANHONG LIU, GUOHUA ZHOU, FENG LI, \\ PINGLI XIE, YUEHUI LI and GUAN-CHENG LI
}

\begin{abstract}
Cancer Research Institute, Key Laboratory of Carcinogenesis and Cancer Invasion Ministry of Education, Key Laboratory of Carcinogenesis Ministry of Health, Central South University, Changsha, Hunan 410078, P.R. China
\end{abstract}

Received January 7, 2013; Accepted May 15, 2013

DOI: $10.3892 / \mathrm{mmr} .2013 .1503$

\begin{abstract}
Golgi phosphoprotein 2 (Golph2) is a type II Golgi-specific membrane protein, which has been found to be overexpressed in hepatocellular carcinoma (HCC) patients. The sensitivity of diagnosis of HCC using Golph2 (76\%) was markedly elevated compared with alpha-fetoprotein (AFP) (70\%), and Golph2 is expected to be a novel and effective serum biomarker for the diagnosis of HCC. The aim of this study was to prepare monoclonal antibodies against Golph2 and to establish double-antibody sandwich enzyme-linked immunosorbent assay (s-ELISA), which will be used in diagnostics, therapeutics and as a tool in understanding the role of Golph2 in the pathogenesis of liver diseases and cancer. In this study, fusion protein TRX-Golph2 was expressed and purified using an Escherichia coli system. BALB/c mice were immunized with TRX-Golph2 recombinant protein. The hybridoma technique was used for the production of anti-Golph2 monoclonal antibody. Hybridoma clones were screened using indirect ELISA and anti-Golph 2 monoclonal antibody was produced in the ascites of BALB/c mice. The specificity of anti-Golph2 monoclonal antibody was detected by western blot analysis and immunocytochemistry. s-ELISA was established using horseradish peroxidase (HRP)-labeled anti-Golph2 monoclonal antibody and used to detect the antigen in the serum of HCC patients. As a result, five stable hybridoma cell clones (5C6D5, 5B7F5, 7F5F3, 8A7B4, 8C9E8) producing anti-Golph2 monoclonal antibody were established. The highest titer of anti-
\end{abstract}

Correspondence to: Professor Guan-Cheng Li, Tumor Immunobiology Laboratory of Cancer Research Institute, Key Laboratory of Carcinogenesis and Cancer Invasion Ministry of Education, Key Laboratory of Carcinogenesis Ministry of Health, Central South University, Changsha, Hunan 410078, P.R. China E-mail: libsun@163.com

*Contributed equally

Key words: hepatocellular carcinoma, Golph2, anti-Golph2 monoclonal antibody, double-antibody sandwich ELISA
Golph2 monoclonal antibody (5C6D5) was 1:51,200. Western blot analysis revealed that anti-Golph 2 monoclonal antibody had a high specificity for Golph2 protein. Anti-Golph2 monoclonal antibody was HRP-labeled and the optimal working concentration was found to be 1:500. The levels of antigen in a proportion of HCC patients were shown to be significantly higher compared to those found in healthy controls.

\section{Introduction}

Hepatocellular carcinoma (HCC) is one of the most common malignant tumors with high malignancy and mortality due to lack of early diagnosis and its resistance to conventional chemotherapy (1). HCC affects approximately one million people every year worldwide, with the incidence equal to the mortality. In 2008, HCC was listed as the third most common cause of cancer-related mortality (2). Thus, early diagnosis is crucial in order to increase the survival rate for patients (3). To date, alpha-fetoprotein (AFP) together with imaging and pathology detection are commonly used in early clinical diagnosis of liver cancer. However, the specificity and sensitivity of AFP for liver cancer screening are not satisfactory. With the development of molecular biology, a number of new types of tumor markers have been discovered.

Golgi phosphoprotein 2 (Golph2) is a type II Golgi-specific membrane protein that is predominantly expressed in the epithelial cells of a number of human tissues (4). In normal human liver, Golph2 is only expressed in biliary epithelial cells and is almost undetected in liver cells. However, increased expression of Golph2 has been reported to be correlated with numerous viral or non-viral infectious liver diseases (5). It was first identified in a search for upregulated hepatic genes in acute giant-cell hepatitis (4)q and then in patients with acute and chronic hepatitis (6). Studies revealed that Golph2 was overexpressed in the serum of HCC patients $(7,8)$. In China, Mao et al first observed that the level of Golph2 in the serum of patients with HCC infected by hepatitis B virus (HBV) was significantly higher than HBV carriers, patients without hepatic diseases and healthy adults (9). In addition, other studies reported that the sensitivity of diagnosis of HCC by Golph2 (76\%) was higher than AFP (70\%), indicating that 
Golph2 may be a novel and effective serum biomarker for the diagnosis of HCC (10).

In the present study, we established hybridoma cell lines that stably secrete anti-Golph2 monoclonal antibody (mAb). Using selected, purified and enzyme-labeled anti-Golph2 $\mathrm{mAb}$, we detected the level of antigen in HCC and healthy samples by double-antibody sandwich enzyme-linked immunosorbent assay (s-ELISA) and expect this method to be used in diagnostics and therapeutics in the future.

\section{Materials and methods}

Subjects. The study protocol was approved by the Central South University's Institutional Review Board, Changsha, Hunan, China and written informed consent was obtained from each subject. Demographic and clinical information was obtained, and a blood sample was collected from each subject. All the subjects were recruited from the clinics at Xiangya Second Hospital, Changsha, Hunan between March 2012 and November 2012. The diagnosis of HCC was made based on guidelines from the Chinese Society of Hepatology, the Chinese Society of Infectious Diseases and the Chinese Medical Association (11-13). A $4 \mathrm{ml}$ blood sample obtained from each subject prior to the initiation of HCC treatment was centrifuged and the serum aliquoted and stored at $-80^{\circ} \mathrm{C}$ until testing ( $\mathrm{n}=30$; age, $54.30 \pm 10.14$ years; HBV-positive). Control subjects were enrolled from staff with no liver disease or risk factors for viral hepatitis, and who were in normal physiological condition $[\mathrm{n}=30$; age, $49.87 \pm 9.23$ years; normal control (NC)]. Balb/c mice were maintained according to institutional animal care and use committee (IACUC-BIDMC) protocols.

Expression, purification and identification of recombinant protein. The recombinant plasmid pET21a(+)-TRX-Golph2, which was constructed in the laboratory, was transformed into Escherichia coli Rosetta (ATCC, Manassas, VA, USA) and optimal expression of recombinant proteins was achieved through controlling the concentration of isopropyl- $\beta-\mathrm{D}$ thiogalactopyranoside (IPTG) and growth conditions. After induction, bacteria were harvested and centrifuged at $4^{\circ} \mathrm{C}$, $4,449 \times \mathrm{g}$ for $10 \mathrm{~min}$, and the pellet was resuspended in $50 \mathrm{mmol} / 1$ sodium phosphate with $0.3 \mathrm{~mol} / 1 \mathrm{NaCl}(\mathrm{pH} 8.0$ ). The resuspended cells were then lysed by sonication and centrifuged at $4^{\circ} \mathrm{C}, 10,012 \mathrm{x} \mathrm{g}$ for $10 \mathrm{~min}$. The expression form of fusion protein TRX-Golph2 was analyzed by sodium dodecyl sulfatepolyacrylamide gel electrophoresis (SDS-PAGE, 12\% gel).

The recombinant protein TRX-Golph2 was further purified by immobilized metal affinity chromatography (MagneHis ${ }^{\mathrm{TM}}$ Protein Purification System; Promega, Madison, WI, USA) under native conditions. The purified protein was dialyzed in $1 \mathrm{X}$ phosphate buffered saline (PBS) at $4^{\circ} \mathrm{C}$ overnight and condensed to a high concentration.

The concentrated recombinant protein was separated by SDS-PAGE on a $12 \%$ polyacrylamide gel and then transferred onto a nitrocellulose membrane (Millipore, Billerica, MA, USA) by electroblotting. Fat-free milk $(5 \%)$ was used to block the membrane at $37^{\circ} \mathrm{C}$ for $2 \mathrm{~h}$. The membrane was then incubated with anti-His tag antibody (1:2,000; Santa Cruz Biotechnology, Inc., Santa Cruz, CA, USA) overnight in a $4^{\circ} \mathrm{C}$ refrigerator. The membrane was then washed with PBS-Tween-20 (PBST) three times and incubated with the horseradish peroxidase (HRP)-conjugated goat anti-mouse secondary antibody $(1: 1,000$, Sigma, St. Louis, MO, USA) in a $37^{\circ} \mathrm{C}$ shaker for $1 \mathrm{~h}$. After washing three times with PBST, the membrane was visualized with an enhanced chemiluminescence (ECL) system (Pierce Biotechnology, Inc., Rockford, IL, USA).

Immunization of mice. Eight-week-old Balb/c mice were immunized three times with purified TRX-Golph2 fusion protein at days 0,21 and 42 with 100, 50 and $50 \mu \mathrm{g}$, respectively, by peritoneal injection. Complete and incomplete Freund's adjuvant $(1: 1$, Sigma) were used to emulsify the protein in the first and other immunizations, respectively. Ten days after the third immunization, mice were bled from the caudal vein and the serum titer was detected by indirect ELISA. Three days after the last booster immunization $(100 \mu \mathrm{g})$, the spleen of the mouse with the highest titer was removed under sterile conditions to prepare a splenic lymphocyte suspension for cell fusion.

Cell culture and fusion. Mouse myeloma cell line SP2/0 was cultured in $10 \%$ fetal bovine serum (Hyclone, Tauranga, New Zealand) and RPMI-1640 medium (Gibco-BRL, Grand Island, $\mathrm{NY}, \mathrm{USA}$ ) in a $37^{\circ} \mathrm{C}, 5 \% \mathrm{CO}_{2}$ incubator. The feeder cells, obtained from the peritoneal cavity of a normal BALB/c mouse by peritoneal injection of RPMI-1640 medium, were plated in 96-well plates and cultured in a $37^{\circ} \mathrm{C}, 5 \% \mathrm{CO}_{2}$ incubator for 1 day prior to fusion. Splenic lymphocytes $\left(1 \times 10^{8}\right)$ were fused with SP2/0 cells $\left(1 \times 10^{7}\right)$ in 50\% polyethylene glycol 1500 (PEG 1500, Sigma-Aldrich, St. Louis, MO, USA). The hybridoma cells were cultured in 96-well plates containing feeder cells and screened by hypoxanthine-aminopterin-thymidine (HAT; Sigma-Aldrich) and cultured in a $37^{\circ} \mathrm{C}, 5 \% \mathrm{CO}_{2}$ incubator. Two weeks later, indirect ELISA using purified TRX-Golph2 protein and HepG2 cells as coating proteins, respectively, was performed to detect the positive clones and then screened clones were recloned by limiting dilution in hypoxanthine-thymidine (HT; Sigma-Aldrich) medium for a further 2 weeks.

Screening of positive clones and cloning. By observing the 96-well plates, we selected a single clone to perform the indirect ELISA using purified TRX-Golph2 protein and HepG2 cells as coating proteins, respectively. The optical density (OD) was read at a wavelength of $405 \mathrm{~nm}$ (microplate reader, Tianshi, Beijing, China) and considered positive when the ratio of OD test to OD control was greater than 3 times. The wells that were positive for both purified TRX-Golph2 protein and HepG2 cells were considered as positive wells and then recloned 3-5 times by limiting dilution until their antibody secretion was $100 \%$. Finally, the positive clones in the 96 -well plates were transferred to 24 -well plates in $10 \%$ fetal bovine serum RPMI-1640 medium. The strain of hybridoma cells that secreted specific mAb was established.

Preparation and titer determination of anti-Golph2 $m A b$. $\mathrm{Balb} / \mathrm{c}$ mice were injected with incomplete Freund's adjuvant $(0.5 \mathrm{ml})$ by peritoneal injection. Three days later, the mice were peritoneally injected with $5 \times 10^{6}$ hybridoma cells diluted by D-Hank's. Ten days later, ascitic fluid was collected and centrifuged at $278 \times \mathrm{g}$ for $5 \mathrm{~min}$ to remove the cellular deposition. Anti-Golph2 mAb in supernatant was diluted 
into different gradients $(1: 100 ; 1: 200 ; 1: 400 ; 1: 800 ; 1: 1,600$; $1: 3,200 ; 1: 6,400 ; 1: 12,800 ; 1: 25,600 ; 1: 51,200)$ and added into 96-well plates coated with TRX-Golph2 antigen, respectively. Indirect ELISA was performed to detect the titer of antiGolph2 mAb. The OD was read at $405 \mathrm{~nm}$.

Subclass determination and purification of anti-Golph $2 \mathrm{mAb}$. The subclass of anti-Golph2 mAb was determined using the SBA Clonotyping System (SouthernBiotech, Birmingham, AL, USA) according to the manufacturer's instructions. The anti-Golph2 mAb (3 ml) was added with equivalent precooled ammonium sulfate overnight in a $4^{\circ} \mathrm{C}$ refrigerator. They were then centrifuged at $4^{\circ} \mathrm{C}, 1,738 \mathrm{x}$ for $15 \mathrm{~min}$. The supernatant was decanted, solubilized by adding PBS (0.02 M, $3 \mathrm{ml})$, and then filtered by Sephacryl S-300 HR gel filtration (Pharmacia, USA). PBS containing $0.02 \% \mathrm{NaN}_{3}$ was used to wash the column and collected components. The positive components confirmed by indirect ELISA were dialyzed in PBS at $4^{\circ} \mathrm{C}$ overnight and condensed to a high concentration. The purity was identified by SDS-PAGE (12\%).

Determination of the relative $m A b$ affinity. A 96-well immunoplate was coated with the TRX-Golph2 fusion protein ( $4 \mu \mathrm{g} / \mathrm{ml})$ at $4^{\circ} \mathrm{C}$ overnight, and then was blocked with $2 \%$ fetal bovine serum at $37^{\circ} \mathrm{C}$ for $2 \mathrm{~h}$. Serial dilutions of the purified $\mathrm{mAb}$ were incubated at $37^{\circ} \mathrm{C}$ for $2 \mathrm{~h}$. The plate was rinsed and incubated with the HRP-conjugated goat anti-mouse antibody (1:4,000 dilution) at $37^{\circ} \mathrm{C}$ for $1 \mathrm{~h}$. After washing, TMB (3,3',5,5'-tetramethylbenzidine) substrate was used for color development. The OD value was measured at $405 \mathrm{~nm}$ in order to determine the relative affinity.

Western blot analysis of anti-Golph $2 \mathrm{mAb}$ specificity. Total proteins extracted from HepG2 cells were separated by SDS-PAGE on a $12 \%$ polyacrylamide gel and then transferred onto a nitrocellulose membrane (Millipore) by electroblotting. Fat-free milk (5\%) was used to block the membrane at $37^{\circ} \mathrm{C}$ for $2 \mathrm{~h}$. The membrane was then incubated with purified antiGolph2 mAb $(1: 2,000)$ overnight in a $4^{\circ} \mathrm{C}$ refrigerator. The membrane was then washed with PBS-Tween-20 (PBST) three times and incubated with the HRP-conjugated goat anti-mouse secondary antibody $(1: 1,000)$ in a $37^{\circ} \mathrm{C}$ shaker for $1 \mathrm{~h}$. After washing three times with PBST, the membrane was visualized with an ECL system (Pierce Biotechnology, Inc.).

Immunocytochemistry. Appropriate amounts of cells were cultured on microslides overnight. When the cells were adherent, slides were fixed with $4 \%$ paraformaldehyde for 15 min. PBST (0.5\%) was used to wash the slides three times. Endogenous peroxidase activity was blocked by $3 \%$ $\mathrm{H}_{2} \mathrm{O}_{2} /$ methanol and non-specific binding was blocked with $2 \%$ BSA-PBS. Diluted anti-Golph2 mAb (50 $\mu \mathrm{l} ; 1: 50)$ was added and incubated overnight in a $4^{\circ} \mathrm{C}$ refrigerator. After three $0.5 \%$ PBST washes, the appropriate (1:200) HRP-conjugated goat anti-mouse secondary antibody was added and incubated at room temperature for $1 \mathrm{~h}$. Slides were washed with $0.5 \%$ PBST three times. Diaminobenzidine (DAB) was added and allowed to react for $1 \mathrm{~min}$. The reaction was stopped by adding water and hematoxylin was added to counterstain for 2 min. Slides were dehydrated with alcohol and mounted with neutral gummi.
Preparation of enzyme-labeled anti-Golph $2 \mathrm{mAb}$. Modified sodium periodate oxidation was used for labeling anti-Golph2 $\mathrm{mAb}(8 \mathrm{~A} 7 \mathrm{~B} 4)$ with high purity. The result and the optimal working concentration of labeled anti-Golph2 mAb with HRP were analyzed by direct ELISA.

Establishment and optimization of double-antibody s-ELISA. A 96-well immunoplate was coated with purified anti-Golph2 $\mathrm{mAb}(5 \mathrm{C} 6 \mathrm{D} 5,20 \mu \mathrm{g} / \mathrm{ml})$ at $4^{\circ} \mathrm{C}$ overnight and then blocked with $2 \%$ BSA-PBS at $4^{\circ} \mathrm{C}$ overnight. After washing plates with PBST three times, serum dilutions $(1: 2,1: 4,1: 8)$, strong positive (50 $\mathrm{ng} / \mathrm{ml}$ antigen), weak positive ( $3 \mathrm{ng} / \mathrm{ml}$ antigen) and negative, were incubated at $37^{\circ} \mathrm{C}$ for $2 \mathrm{~h}$, respectively. The plates were washed three times and enzyme-labeled anti-Golph2 mAb (1:300, 1:400, 1:500, 1:600) was added and the plates were incubated at $37^{\circ} \mathrm{C}$ for $1 \mathrm{~h}$. The plates were washed again and colored with $100 \mu \mathrm{l}$ 2,2-Azinobis (3-ethylbenzothiazoline-6-sulfonic acid) diammonium salt (ABTS; Boehringer Mannheim $\mathrm{GmbH}$, Germany) for $25 \mathrm{~min}$ at $37^{\circ} \mathrm{C}$. The OD was read at a wavelength of $405 \mathrm{~nm}$. A chessboard titration method was designed to examine the optimal working concentration of HRP-labeled mAb and the dilution ratio of serum.

Analysis of serum samples by s-ELISA. The expression level of Golph2 in serum dilutions was analyzed by s-ELISA.

Statistical analysis. All of the values which presented as the mean of three paralleled individual experiments were entered into SPSS 13.0 software. The mean and standard deviation (SD) of the OD of individual groups were calculated. The expression of Golph2 in serum was described using box-andwhisker plots. The difference between groups was analyzed using Student t-tests. $\mathrm{P}<0.05$ was considered to indicate a statistically significant result.

\section{Results}

Expression, purification and identification of recombinant protein. The recombinant fusion protein was expressed under the optimizing prokaryotic expression conditions of $1 \mathrm{mM}$ IPTG, $30^{\circ} \mathrm{C}, 2 \mathrm{x} \mathrm{g}$, for $10 \mathrm{~h}$ and purified by immobilized metal affinity chromatography under native conditions. The expressed and purified protein were identified by $12 \%$ SDS-PAGE and subsequently stained with Coomassie Brilliant Blue R250 (Fig. 1). The molecular weight of TRX-Golph2 protein was $\sim 73 \mathrm{kDa}$. The protein was then further identified by western blot analysis using anti-His tag antibody (Fig. 2).

Establishment of hybridoma cell lines and preparation of anti-Golph $2 \mathrm{mAb}$. Through the procedures of immunization, fusion and clone selection, five hybridoma cell lines (5C6D5, 5B7F5, 7F5F3, 8A7B4, 8C9E8) that stably secreted anti-Golph2 $\mathrm{mAb}$ were obtained. The identity, subclass and titer are shown in Table I.

Investigation of $m A b$ relative affinity. The relative affinities of mAbs were defined by the antibody concentration at which the OD value reached half the maximal signal at the plateau stage of antigen-antibody binding. The results revealed that 


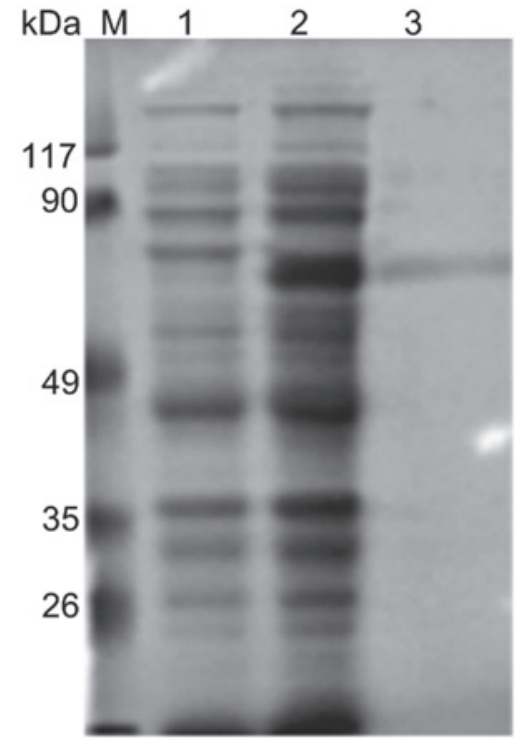

Figure 1. The expression of unpurified and purified TRX-Golph2 fusion protein in Escherichia coli was analyzed by SDS-PAGE (12\% gel). Proteins were visualized by Coomassie Blue R-250 staining. M, protein molecular weight marker; lane 1, pET-21(a)-TRX-Golph2 product without IPTG induction in Rosetta; lane 2, pET-21(a)-TRX-Golph2 product induced in Rosetta; lane 3, purified TRX-Golph2; Golph2, Golgi phosphoprotein 2; IPTG, isopropyl- $\beta$ D-thiogalactopyranoside.

\section{$73 \mathrm{kDa}$}

Figure 2. Western blot analysis of purified product. Identification of proteins was confirmed by western blot assay using anti-His tag $\mathrm{mAb}$. mAb, monoclonal antibody.

the order of relative affinity of the five selected $m A b s$ was 8A7B $>5$ C6D5 $>$ 5B7F5 $>$ 8C9E8 $>7$ F5F3 (Fig. 3).

Purification of anti-Golph2 $m A b$. The anti-Golph2 $\mathrm{mAb}$ was purified by Sephacryl S-300 HR gel filtration. After dialyzing and condensing, the purity was identified by SDS-PAGE (12\%) (Fig. 4).

The specificity of anti-Golph $2 \mathrm{mAb}$. Immunocytochemistry (HepG2) revealed that the membrane of the Golgi was positively stained (Fig. 5A and B). By western blot analysis, anti-Golph2 mAb (8A7B4) was shown to react specifically with Golph2 protein $(45 \mathrm{kDa})$ in accordance with the theoretical value (Fig. 5C).

Preparation of enzyme-labeled anti-Golph2 $m A b$. The anti-Golph2 mAb (8A7B4) was labeled with HRP by modified sodium periodate oxidation. By direct ELISA, the working concentration of labeled $\mathrm{mAb}$ was shown to be 1:500.

Establishment and optimization of double-antibody s-ELISA. One serum sample from a known patient with overexpression of Golph2 in serum was used for the determination of the dilution ratio of serum. The optimal working concentration of HRP-labeled $\mathrm{mAb}$ and the dilution ratio of serum were fixed
Table I. Characterization of anti-Golph2 protein mAbs.

\begin{tabular}{lcr}
\hline Clone name & Titer & Subclass \\
\hline 5B7F5 & $1: 25600$ & $\operatorname{IgM}(\lambda)$ \\
5C6D5 & $1: 51200$ & $\operatorname{IgM}(\kappa)$ \\
7F5F3 & $1: 25600$ & $\operatorname{IgM}(\kappa)$ \\
8A7B4 & $1: 12800$ & $\operatorname{IgG1}(\kappa)$ \\
8C9E8 & $1: 25600$ & $\operatorname{IgM}(\lambda)$
\end{tabular}

Golph2, Golgi phosphoprotein 2; mAbs, monoclonal antibodies.

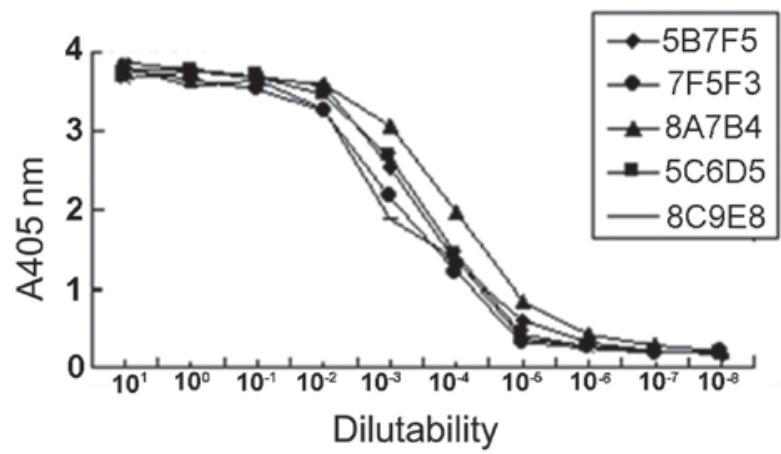

Figure 3. Relative affinities of anti-TRX-Golph2 fusion protein mAbs for the TRX-Golph2 fusion protein were analyzed by indirect ELISA assay of the serially diluted mAb. Golph2, Golgi phosphoprotein 2; ELISA, enzyme-linked immunosorbent assay; mAbs, monoclonal antibodies.

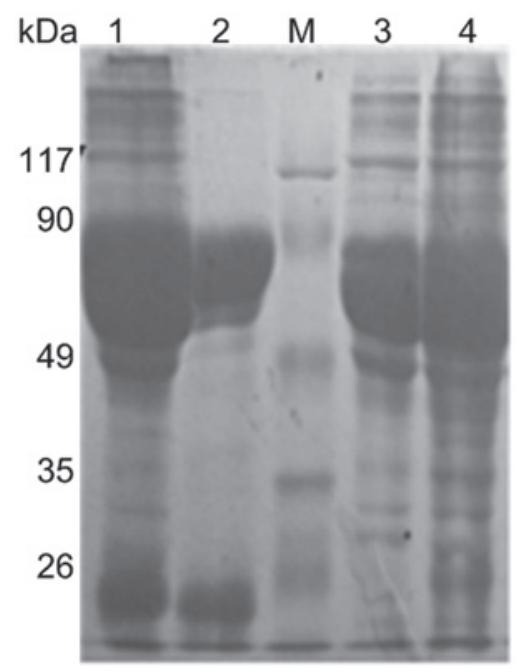

Figure 4. Purification of anti-Golph2 monoclonal antibody was analyzed by SDS-PAGE (12\% gel). Lane 1, ascitic fluid containing 8A7B4 mAb; lane 2, purified 8A7B4 mAb; M, protein molecular weight marker; lane 3, purified 5C6D5 mAb; lane 4, ascitic fluid containing 5C6D5 mAb; Golph2, Golgi phosphoprotein 2; mAb, monoclonal antibody.

on $1: 500$ and $1: 2$, respectively, by the chessboard titration method (Table II).

Detection of serum. The levels of antigen in the samples were detected by s-ELISA using HRP-labeled anti-Golph2 $\mathrm{mAb}$ (Fig. 6). The median serum level of Golph2 in the HCC group 
Table II. Selection of the optimal working concentrations of HRP-marked mAb and the optimum serum dilution.

\begin{tabular}{lcccccc}
\hline & \multicolumn{5}{c}{ OD $_{405}$} \\
\cline { 2 - 7 } $\begin{array}{l}\text { Dilution of } \\
\text { HRP-marked mAb }\end{array}$ & $\begin{array}{c}\text { Serum dilutions } \\
(1: 2)\end{array}$ & $\begin{array}{c}\text { Serum dilutions } \\
(1: 4)\end{array}$ & $\begin{array}{c}\text { Serum dilutions } \\
(1: 8)\end{array}$ & $\begin{array}{c}\text { Strong positive } \\
(50 \mathrm{ng} / \mathrm{ml})\end{array}$ & $\begin{array}{c}\text { Weak positive } \\
(3 \mathrm{ng} / \mathrm{ml})\end{array}$ & Negative \\
\hline $1: 300$ & 1.256 & 0.637 & 0.287 & 1.029 & 0.195 & 0.156 \\
$1: 400$ & 0.869 & 0.437 & 0.228 & 0.749 & 0.117 & 0.115 \\
$1: 500$ & 0.627 & 0.315 & 0.149 & 0.573 & 0.095 & 0.094 \\
$1: 600$ & 0.435 & 0.373 & 0.157 & 0.403 & 0.084 & 0.089 \\
\hline
\end{tabular}

HRP, horseradish peroxidase; mAb, monoclonal antibody.

A

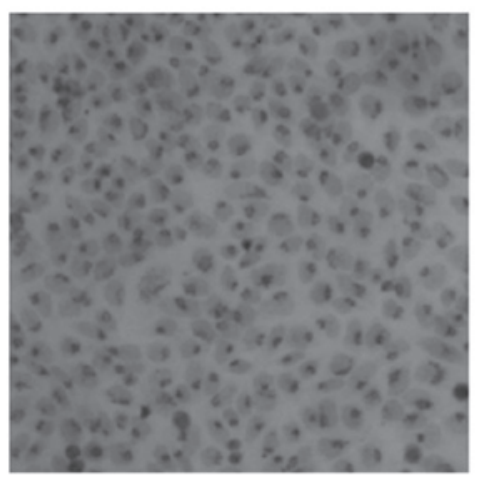

B

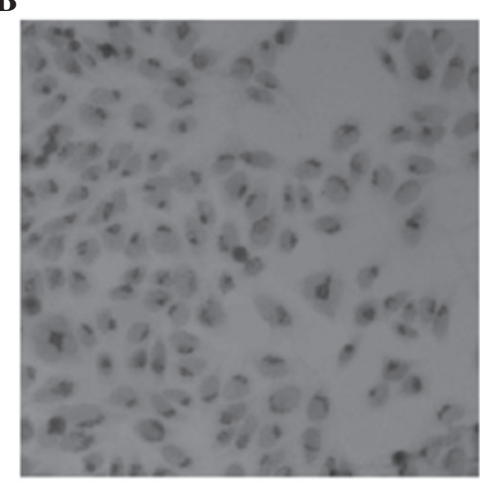

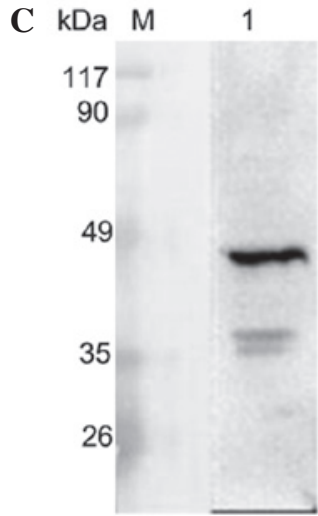

Figure 5. Immunocytochemistry and western blot analysis of ascitic fluid. (A and B) Immunocytochemistry (HepG2) analysis of ascitic fluid (A, 8A7B4 mAb; B, 5C6D5 mAb). (C) Western blot analysis of ascitic fluid. M, protein molecular weight marker; lane 1, cell lysis solution of HepG2 was recognized by antiTRX-Golph2 fusion protein mAb (8A7B4). mAb, monoclonal antibody; Golph2, Golgi phosphoprotein 2.

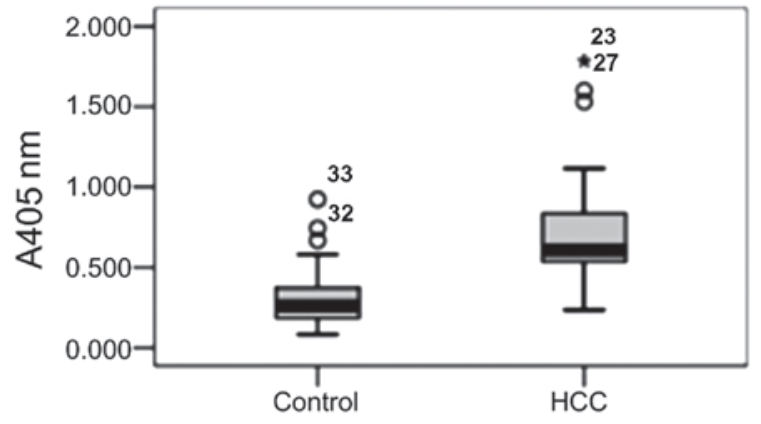

Figure 6. Levels of serum antigen were analyzed by s-ELISA and the $\mathrm{OD}_{405}$ value is shown. Serum from HCC patients and healthy subjects was tested simultaneously and serum dilution was 1:2. HCC, hepatocellular carcinoma; s-ELISA, sandwich enzyme-linked immunosorbent assay.

significantly exceeded that of the healthy controls $(\mathrm{P}<0.05)$. As shown in Fig. 6, the average serum content of Golph2 in HCC patients is $>100 \mu \mathrm{g} / 1$, consistent with other studies using s-ELISA (8).

\section{Discussion}

Since it was first identified in acute giant-cell hepatitis, tissue-based Golph2 overexpression has been confirmed in HCC $(8,14)$, lung adenocarcinoma (15), seminomas (16), renal cell cancer (17) and other malignant diseases. Notably, a large number of studies have indicated that the serum level of Golph2 may be a more reliable biomarker for the early diagnosis of HCC than AFP. Previous studies have showed that Golph2 is an adenovirus-induced cellular protein whose expression is regulated through E1A protein $(4,18)$. Golph2 overexpression, intracellular trafficking between the Golgi and plasma membrane through an endosomal pathway, and the cleavage of Golph2 may explain the secretion of Golph2 (19). However, the exact mechanism involved remains unclear. mAbs against Golph2 prepared in this study lay a foundation for further investigation of the interaction between antigen epitopes and antibodies, and provide a tool for determining the Golph2 secretion mechanism.

In our study, the E. coli system Rosetta was selected to express Golph2 protein. When using a prokaryotic system, it is difficult to express the full length of Golph2. The Rosetta system contains rare codon tRNA that improves protein expression, allowing Golph2 to be expressed. We selected pET21a(+)-TRX as the prokaryotic expression vector. TRX is a thioredoxin and is widely used in molecular cloning expression. TRX protein prevents the target protein from being degraded by endoproteinase and provides the ligand binding sites for affinity purification. Furthermore, TRX contributes to folding of the target protein and increases its soluble expression. The fusion protein TRX-Golph2 can be expressed under native 
conditions. SDS-PAGE showed that the fusion protein had a $78 \mathrm{kDa}$ band. This is not in accordance with the theoretical value, as Golph2 has abundant acidic amino acids (PI=4.72), which causes the migration rate of the recombinant protein to decline in the denatured SDS-PAGE (20). After induction and purification, we successfully obtained TRX-Golph 2 in the soluble form.

Using mAb technology with high purity and good reproducibility $(21,22)$, we selected five hybridoma cell lines that stably secreted anti-Golph $2 \mathrm{mAb}$. Two strains of relatively high affinity $\mathrm{mAb}$ were selected and analyzed by western blot analysis and immunocytochemistry. Western blotting showed that the $\mathrm{mAb}$ recognized Golph2 protein specifically. Immunocytochemistry revealed that Golph2 is located in the membrane of the Golgi. The mAb with higher purity was labeled with HRP. The concentration of the coated antibody was fixed at $20 \mu \mathrm{g} / \mathrm{ml}$, and the optimal working concentration of HRP-labeled $\mathrm{mAb}$ and the dilution ratio of serum was confirmed to be 1:500 and 1:2, respectively, using the chessboard titration method in s-ELISA.

Double-antibody s-ELISA is commonly used for testing antigens. In the present study, HRP-labeled $\mathrm{mAb}$ with different epitopes from coated $\mathrm{mAb}$ was produced for the first time. Previous studies on Golph2 in serum used enzyme-labeled anti-Golph2 polyclonal antibody or a combination of anti-mAb with enzyme-labeled anti-IgG to perform the double-antibody s-ELISA (8). Polyclonal antibody has a high level of cross reaction and can generate false positive results, while $\mathrm{mAb}$ has high specificity and accuracy. Therefore, our s-ELISA had significantly higher sensitivity and specificity than the previous studies. Results showed that the expression level of serum Golph2 in patients with HCC was markedly higher than that in healthy individuals.

In conclusion, mAbs and s-ELISA against Golph2 may be useful tools for the sensitive and specific diagnosis of HCC. The preparation of humanized antibody has been published previously (23), whereas the optimization of humanized antibody requires further research. This study provides the basis for optimization of humanized antibody.

\section{Acknowledgements}

This study was supported by the National Natural Science Foundation of China (NSFC)-973 Project (2010CB833605).

\section{References}

1. Siegel R, Naishadham D and Jemal A: Cancer statistics. CA Cancer J Clin 62: 10-29, 2012.

2. El-Serag HB, Marrero JA, Rudolph L and Reddy KR: Diagnosis and treatment of hepatocellular carcinoma. Gastroenterology 134: 1752-1763, 2008.
3. Trinchet JC, Alperovitch A, Bedossa P, Degos F, Hainaut P and Beers BV: Epidemiology, prevention, screening and diagnosis of hepatocellular carcinoma. Bull Cancer 96: 35-43, 2009.

4. Kladney RD, Bulla GA, Guo L, et al: GP73, a novel Golgilocalized protein upregulated by viral infection. Gene 249: 53-65, 2000.

5. Gu Y, Chen W, Zhao Y, Chen L and Peng T: Quantitative analysis of elevated serum Golgi protein-73 expression in patients with liver diseases. Ann Clin Biochem 46: 38-43, 2009.

6. Iftikhar R, Kladney RD, Havlioglu N, et al: Disease- and cell-specific expression of GP73 in human liver disease. Am J Gastroenterol 99: 1087-1095, 2004.

7. Riener MO, Stenner F, Liewen H, et al: Golgi phosphoprotein 2 (GOLPH2) expression in liver tumors and its value as a serum marker in hepatocellular carcinomas. Hepatology 49: 1602-1609, 2009.

8. Tian L, Wang Y, Xu D, et al: Serological AFP/Golgi protein 73 could be a new diagnostic parameter of hepatic diseases. Int J Cancer 12: 1923-1931, 2011.

9. Mao Y, Yang H, Xu H, et al: Golgi protein 73 (GOLPH2) is a valuable serum marker for hepatocellular carcinoma. Gut 59: 1687-1693, 2010.

10. Zhou Y, Yin X, Ying J and Zhang B: Golgi protein 73 versus alpha-fetoprotein as a biomarker for hepatocellular carcinoma: a diagnostic meta-analysis. BMC Cancer 12: 17, 2012.

11. Chinese Society of Hepatology. 2004 Guidelines for surgical treatment of primary hepatocellular carcinoma. Zhonghua Gan Zang Bing Za Zhi 13: 329-330, 2005.

12. Chinese Society of Infectious Diseases. The guidelines of prevention and treatment for chronic hepatitis B. Zhonghua Gan Zang Bing Za Zhi 13: 881-891, 2005.

13. Chinese Medical Association. Guideline of prevention and treatment of hepatitis C. Zhonghua Yu Fang Yi Xue Za Zhi 38: 210-215, 2004.

14. Shi Y, Chen J, Li L, et al: A study of diagnostic value of golgi protein gp73 and its genetic assay in primary hepatic carcinoma. Technol Cancer Res Treat 10: 287-294, 2011.

15. Zhang F, Gu Y, Li X, Wang W, He J and Peng T: Up-regulated Golgi phosphoprotein 2 (GOLPH2) expression in lung adenocarcinoma tissue. Clin Biochem 43: 983-991, 2010.

16. Fritzsche FR, Kristiansen G, Riener MO, Dietel M and Oelrich B: GOLPH2 expression may serve as diagnostic marker in seminomas. BMC Urol 10: 4, 2010.

17. Fritzsche FR, Riener MO, Dietel M, Moch H, Jung K and Kristiansen G: GOLPH2 expression in renal cell cancer. BMC Urol 8: 15, 2008.

18. Kladney RD, Tollefson AE, Wold WS and Fimmel CJ: Upregulation of the Golgi protein GP73 by adenovirus infection requires the E1A CtBP interaction domain. Virology 301: 236-246, 2002.

19. Hu L, Li L, Xie H, Gu Y and Peng T: The Golgi localization of GOLPH2 (GP73/GOLM1) is determined by the transmembrane and cytoplamic sequences. PLoS One 6: e28207, 2011.

20. Gong Y, Long Q, Xie H, Zhang T and Peng T: Cloning and characterization of human Golgi phosphoprotein 2 gene (GOLPH2/ GP73/GOLM1) promoter. Biochem Biophys Res Commun 421: 713-720, 2012.

21. Köhler G and Milstein C: Continuous cultures of fused cells secreting antibody of predefined specificity. Nature 256: 495-497, 1975.

22. Gerdes J, Lemke H, Baisch H, et al: Cell cycle analysis of a cell proliferation-associated human nuclear antigen defined by the monoclonal antibody Ki-67. J Immunol 133: 1710-1715, 1984.

23. Li F, Liu YH, Li YW, et al: Construction and development of a mammalian cell-based full-length antibody display library for targeting hepatocellular carcinoma. Appl Microbiol Biotechnol 96: 1233-1241, 2012. 